\title{
Pornography: A Sociobiological Attempt at Understanding
}

\author{
Joseph Shepher \\ Neuropsychiatric Institute, University of California, Los Angeles
}

Judith Reisman (Bat Ada)*

The American University, Washington, D.C.

\begin{abstract}
It is now generally conceded that humans engage in sexually dimorphic mating strategies, due largely to the high female versus the low male genetic investment in the rearing of offspring. This uneven investment has, arguably, led to: a) female preference for monogamously receptive males who are prepared to protect and nurture the female and their mutual offspring, and b) male requirements that the chosen female assure the investor of his paternity. Pornography is addressed here as media information delivery of a physiological arousal experience with roots in male sexual strategy/fantasy. Should pornography sufficiently arouse a biologically determined male predisposition for polygamy, then its informational system may be contributing to contemporary male frustration and even aggressivity toward the female in general and monogamous patterns of sexuality in particular. It may be argued that if the visual data of pornography encourages distrust of female sexual fidelity and a distorted perception of female personhood, such data could encourage disdain and/or animosity toward heterosexual comradeship and the value of such comradeship for individual and social solvency.
\end{abstract}

Key Words: Pornography, arousal, sexuality, aggresivity, fantasy, sociobiology.

The scientific debate on pornography has focused for a very long time on questions of policy (should pornography be permitted or prohibited?). Policy makers usually ask: Does it harm

Address reprint requests to: Dr. J. A. Reisman, The American University, 5010 Wisconsin Ave., Washington D.C. 20816.

*Editors' note: Professor Joseph Shepher unexpectedly died in Los Angeles, California, March 28, 1984. The final revision of this article was undertaken by Dr. Judith Reisman. the individual and impair the social order by disseminating depictions of sexual perversions and sexual aggression, especially (or exclusively) against women? Conversely, does it work as a security valve, defusing potentially explosive sexual energies? Does pornography destroy normal, harmonious, male-female relationships by dehumanizing the female, or does it improve these relationships by removing moralistic inhibition from potentially mutually satisfying erotic behavior?

Heated discussion of these questions has been fueled by many preconceived ideas-from the patriarchal conspiracy of men anxious to maintain their disintegrating domination of women to the sacred vow of liberals to save freedom of expression from the attack of religious moralists to fervent feminists. Yet comparatively little effort is devoted to an understanding of the phenomenon. Such understanding may be the key to an objective evaluation of questions of the social value of pornography and questions of policy.

Supporters and antagonists would both agree that pornography is a commodity for which millions of people in the Western world are prepared to pay billions of dollars every year. Pornographic pictures, novels, films, casettes, records, and devices are sold in thousands of specialty shops, with a hierarchy of levels, styles, and prices for the products.

Pornography in its present dimensions is a recent phenomenon characterizing the Western world and dissipating from it to the communist and Third World nations. Pornography existed 
both in Europe and in the great Eastern cultures of India, Japan, China, and Islam, but its use was limited to a small group of gentry, courtiers, or wealthy middle class. Now is the first time in history that pornography is mass produced and mass consumed.

\section{PORNOGRAPHY AND HUMAN.SEXUALITY ${ }^{1}$}

In order to avoid becoming mired in the complex debate on the definition of pornography-a word that, to date, has appeared undefinablelet us consider two essential features stated by a historian of pornography, Montgomery Hyde (1965): pornography deals with some aspect of sexuality and it has the power to arouse the viewer, who labels this arousal as "sexual." By these criteria, then, Thomas Mann's description of the wedding night of Jacob and Leah in The Tales of Jacob, the first book in his tetratrology, Joseph and His Brothers, could be pornographic, since it has been known to bring a sixteen-year-old to a heightened sexual arousal. Most judges, of course, would not consider this writing pornographic.

This raises the question of distinction between eroticism and pornography. We might use Merton's (1949) distinction between intended (overt) and unintended (latent) functions. Pornography is intended genital arousal, whereas eroticism in art and literature is unintended arousal. One problem, however, is that intentions are not easy to be proven empirically. Nevertheless, it is plausible to assume that Thomas Mann did not intend to excite genital arousal in his readers, nor did Goya by painting Maya Desnuda, whereas most people would agree that the author of Fanny Hill and photographers of Hustler had such intentions. Thus the distinction-to date-still remains a matter of consensus.

Although some feminist critics of pornography addressed "nonviolent" depictions as often

\footnotetext{
${ }^{1}$ We limit the word sexuality to adult heterosexual behavior. The issues of homosexuality, bisexuality, and child sexuality as well as sexual aberrations are important but we cannot deal with them in the framework of one, comparatively short article. We shall return to them marginally later, when discussing the dynamics of pornography.
}

critical antihuman messages (Bat Ada 1980), most feminist critics focused on elements of degradation, humiliation, and torturing of females in pornography (Griffin 1981; Dworkin 1981; Diamond 1980). These elements are widely present both in written and pictorial pornography but they are by no means universal. However, feminist writers rightly pointed to the direction toward which pornography is frequently pushed, as we shall explain later.

Based upon our limited understanding of the pornographic process, we may say that pornography here is a media information delivery system in which human females, nude or seminude, simulate "estrus" via mating display/presenting postures reflecting male sexual strategy/fantasy. The cross cultural complexity of pornography, feminists argue, still finds its expression and root in abuse of women.

Feminists argue that the cross-cultural complexity and tendency of violence to women finds its expression in western pornography. This view is illuminated by the recent efforts in Minneapolis to legislate against mass distribution and sale of sexually violent and "degrading" images of women as a "discriminatory practice" and thus a violation of women's civil rights. It may be of some interest to quote from this controversial proposed city ordinance.

Specialfindings on pornography: The Council finds that pornography is central in creating and maintaining sex as a basis for discrimination. Pornography is a systematic practice of exploitation and subordination based on sex which differentially harms women. This harm includes de-humanization, sexual exploitation, forced sex, forced prostitution, physical injury, and social and sexual terrorism and inferiority presented as entertainment. The bigotry and contempt it promotes, with the acts of aggression it fosters, diminish opportunities for equality of Rights in Employment, Education, Property Rights, Public Accomodations, and Public Services; create publish and private harassment, persecution and denigration; promote injury and degradation such as rape, battery and prostitution and inhibit just enforcement of laws against these acts; contribute significantly to restricting women in particular from full exercise of citizenship and participation in public life, including in neighborhoods; damage relations between the sexes; and undermine women's equal exercise of rights to speech and action guaranteed to all citizens under the Constitutions and laws of the United States and the State of Minnesota. 
Although the definition of pornography is, largely, culture bound, and, to some extent, one may even say that sexuality and sexual excitement are so bound, no culture denies sexuality completely, though all cultures regulate it in certain ways. Sexual excitement is a condition sine qua non of heterosexual intercourse, at least for males, and a highly beneficial if not indispensable condition for females, who want to enjoy intercourse and not only endure it. On the other hand, pornography is certainly not a necessary condition of sexual excitement.

\section{THE CONSUMERS OF PORNOGRAPHY}

Pornography is consumed in many forms: books, journals, pictures, wide screen films, records, cassettes, video cassettes, and live shows. Reliable data exist only on the consumption of one of these media: journals.

Readership data on 13 leading magazines provided by the authoritative Target Group Index (TGI) $(1974,1978)$ is given in Table 1.

We have not included any of the specific "male" magazines, such as American Legion, Car Craft, Road and Track, and Workbasket; or "female" magazines, such as Baby Talk, Better Homes and Gardens, Family Circle, Glamour, Good Housekeeping, House and Garden, La- dies' Home Journal, McCall's, Vogue, and Woman's Day.

The following conclusions can be deduced from the figures:

1. The four leading pornographic magazines have a readership of 19-40 million, and this readership has grown $10 \%$ between 1974 and 1978 (from $36,302,000$ to $39,410,000$ ). The aggregate readership of all the rest has grown only by $8 \%$ (from $145,107,000$ to $156,113,000$ ).

2. The sex ratio of the adult readership is highly male biased in the four male pornographic magazines and becomes more so during the years. Oui, which was extremely male biased in 1974, increased female readership perhaps due to the aging and subsequent marriage of numbers of its youthful male readership. Increasingly brutal since 1978, it apparently was sold by Playboy Enterprises to another syndicate.

The range of the male-to-female sex ratio is between 3.43 and 5.96. The aggregate sex ratio in 1978 is $4.3(31,998,000$ males as against $7,410,000$ females).

3. None of the other general interest magazines show considerable sex bias: the highest ratio is 1.69 (Esquire in 1978), the lowest 0.72 (Reader's Digest in 1978).

Table 1. Total Adult, Male Adult, and Female Adult Readership of Selected Magazines 1974, 1978 and the Sex Ratio of Readership (in thousands) ${ }^{a}$

\begin{tabular}{|c|c|c|c|c|c|c|c|c|c|c|c|}
\hline \multirow[b]{2}{*}{ Magazine } & \multicolumn{3}{|c|}{ Total Adult Readership } & \multicolumn{3}{|c|}{ Male Adult Readership } & \multicolumn{3}{|c|}{$\begin{array}{l}\text { Female Adult } \\
\text { Readership }\end{array}$} & \multicolumn{2}{|c|}{$\begin{array}{c}\text { Sex Ratio } \\
\text { M/F }\end{array}$} \\
\hline & 1974 & 1978 & $\%$ Change & 1974 & 1978 & $\%$ Change & 1974 & 1978 & $\%$ Change & 1974 & 1978 \\
\hline Penthouse & 9104 & 10713 & +18 & 7039 & 8944 & +27 & 2065 & 1768 & -14 & 3.41 & 5.0 \\
\hline Playboy & 18901 & 18423 & -2 & 13425 & 14272 & +6 & 5449 & 4151 & -24 & 2.44 & 3.4 \\
\hline Newsweek & 16810 & 16197 & -4 & 8946 & 9107 & +2 & 7865 & 7090 & -10 & 1.13 & 1.2 \\
\hline Time & 16643 & 19215 & +15 & 8920 & 10165 & +14 & 7723 & 9051 & +17 & 1.15 & 1.1 \\
\hline Oui & 3297 & 3760 & +14 & 3142 & 3220 & +2 & 155 & 540 & +248 & 20.2 & 5.9 \\
\hline New Yorker & 2297 & 2117 & -8 & 1003 & 1027 & +2 & 1294 & 1090 & -16 & 0.77 & 0. \\
\hline Esquire & 3378 & 3868 & +15 & 1912 & 2432 & +27 & 1466 & 1435 & -2 & 1.31 & 1.6 \\
\hline Ebony & 5164 & 5217 & +1 & 2410 & 2396 & -0.5 & 2754 & 2821 & +2.4 & 0.87 & 0.8 \\
\hline Playgirl & 5842 & 3780 & -35 & 2543 & 1580 & -38 & 3300 & 2201 & -33 & 0.77 & 0.7 \\
\hline National Geographic & 17808 & 21980 & +23 & 9132 & 11122 & +22 & 8676 & 10858 & +25 & 1.05 & 1.0 \\
\hline TV Guide & 42256 & 44136 & +4 & 18227 & 20330 & +12 & 24029 & 23806 & -1 & 0.75 & 0.8 \\
\hline Reader's Digest & 40751 & 43383 & +6 & 17989 & 18091 & +0.5 & 22762 & 25292 & +11 & 0.78 & 0.7 \\
\hline $\begin{array}{l}\text { Hustler (1974 } \\
\text { estimate) }\end{array}$ & 5000 & 6514 & +30 & 4270 & 5562 & +30 & 730 & 951 & +30 & 5.85 & 5.8 \\
\hline
\end{tabular}

a Source: Target Group Index (1974, 1978, Vol. M-1, Table 1), based on a nationwide sample of 30157 respondents. Hustler 1974 estimated by Hustler Magazine. 
4. Interestingly, Playgirl, the pornographic magazine for women, has only a slightly female biased ratio 0.72 in 1978 . This indicates that females are not a good target for pornography. The reciprocal of this ratio is 1.39. Almost two and one half million males read Playgirl, presumably homosexual males (Symon 1979, pp 174-175).

The following characteristics of the readership of pornography can be compiled from the 1978 TGI:

1. More than two thirds of the recorded male readership is between the ages of 18 and 34 , whereas only $41.8 \%$ of the general male readership is in this age group (TGI 1978, pp. 122 124). We have no figures to date on the adolescent male readership although anecdotal information strongly suggests a significant young male reading population.

2. Close to $80 \%$ of the male readership is metropolitan, as against $71.4 \%$ of the general male readership (TGI 1978, pp. 190-192).

3. Almost $50 \%$ of the male readership are college educated, as against $33.8 \%$ of the general male readership (TGI 1978, 122-124).

4. Almost $60 \%$ of the male readership is married, as against $70.4 \%$ of the general male readership (TGI 1978, pp. 202-204).

5. About $70 \%$ of the female readership of pornographic magazines is married, as against $62.9 \%$ of the general female readership (TGI 1978, pp. 426-428). The readership for all five pornographic magazines presented in Table 1 is estimated as follows:

$$
\begin{array}{lr}
\text { Male } & 33,578,000 \\
\text { Female } & 9,611,000 \\
\hline & 43,189,000
\end{array}
$$

The age group of 18-64 comprises $130,846,000$ people, the sex ratio is 0.97 , that is, $67,100,510$ females and 63,745,490 males (Statistical Abstracts of United States 1979, p. 8). As we have seen, the sex ratio of the pornographic clientele averages on 3.5. Thus, if we presume that the 34 million male readers represented 43 million discrete individuals, then we would have to assume that $53 \%$ of all adult males are pornography consumers. However, since some portion of all pornography readership is crossover, that is, some read one or more pornographic magazines, we cannot accurately de- termine the percentages of American males who are regular versus occasional consumers. Still, since two thirds of the male readers are in the young age group, one can estimate that a large proportion of younger versus older males in the American population are consumers of pornography.

\section{MALE SEXUAL STRATEGY}

One can postulate that males apparently need more genital stimulation than do females. Symons (1979) explains this by the fact that males seem to have a high need for sexual variance. Thus males are more easily excited by visual stimuli, a trait possibly connected with the lower male parental investment in the offspring. Since a male can hope for offspring from every sexual intercourse with a fertile female, he seems biopsychologically programmed to be readily excited whenever an opportunity offers itself. One wonders whether this explains the higher androgen hormone content circulating in his blood? Androgens are thought to promote sexual drive (libido) in both females and males (Baum et al. 1977).

Yet the range of male strategies is much wider than that. Its actual pattern is dependent on the mating system of the species, which again is an adaptation to the specific ecological conditions in which the species lives. In a polyandrous bird like the jacana (Iacana spinosa), the above-mentioned male strategy would be disastrous to the genetic fitness of the males (Daly and Wilson 1978, pp. 112-113.

Mammals in general, and primates in particular (among whom polyandry is practically nonexistent except among humans under certain circumstances), adopt different mating systems that dictate different male strategies. Hrdy (1981, pp. 34-35) found 37 monogamous species, roughly $18 \%$, among 200 odd species of primates. For a monogamous male, it would be dysfunctional to be easily excited and searching for many mates. The ecological conditions of such a species call for constant male parental investment, without which the male cannot hope for surviving offspring, no matter how many females if any he eventually succeeds in fertilizing.

Hrdy $(1981$, p. 37$)$ categorizes humans as facultative monogamists; that is, depending on environmental factors, they condone either monogamous or polygynous arrangements. And, 
while females might happily condone polyandry, there has been no evidence to suggest that male societies long permit such an arrangement. One has to add that, among primates, the only terrestrial species living in faculative monogamy is the human. All other primate monogamous species are forest-dwelling arboreal. Does not the isolated Western nuclear family seem to be a reminder of the gibbon couple? Whereas the environmental factors in animal species are hardly manipulative, human adaptation to environmental conditions is flexible, albeit not totally. The polygyous tendency in human males can be said to act as epigenetic rule (Lumsden and Wilson 1981), creating a highly biased ethnographic frequency distribution of human mating patterns. Among 847 human cultures, 708 (83.4\%) were found to condone polygyny, $137(16 \%)$ monogamy, and $4(0.47 \%)$ polyandry (Murdock 1967). About half of the polygynous cultures permit polygyny, but actually not many males are married polygynously. The other half practices systematic polygyny. The rarity of polyandry is especially conspicuous, reflecting the complete absence of this mating system among nonhuman mammals.

Although cultural evolution constrained the human male to adapt to environmental situations in which monogamy-and even polyandrywere advantageous, he remained basically polygynous. Both his physiological-hormonal and his psychological structures would then seem to be geared to a polygynous life. Under monogamous and, especially, polyandrous conditions, he can be seen to have to cope with certain new tensions. Their management would then require different mechanisms of behavioral tension release, many of these management stratagies having formed cultural patterns. The polyandrous unit easily transmutes into monogamous or polygynandrous (that is, more than one male with more than one female) marriages as soon as the ecological pressure eases. The ubiquitous flourishing of female prostitution in monogamous societies may be viewed as an instructive example of how general male behavioral tendencies may become culturally institutionalized (though prostitution exists in polygynous societies, for example, among the Hausa).

It has been suggested that the foregoing brief paragraph attempts to do no less than to account for the character of human evolution. Although certainly we are aware of the brevity of the ar- gument as presented, this is not to suggest our false assurance of having solved the problem of the ages, but rather to conform to the demands of the article's length-a less extravagant but more realistic aim. How are polygynous predispositions associated with pornography? We would argue that polygynous tendencies prompt human males to seek multiple female partners, which is not easy to achieve, even in a polygynous culture, because of the limiting factor of the sex ratio. Unless this ratio is highly depressed (that is, that there is a considerable surplus of females), polygyny is possible only by preventing many males from mating.

This condition, again, is very difficult to sustain, unless power is universally distributed among males. Although depressed sex ratio is a reccurrent event after major wars, in which many males are killed, it is a transient phenomenon, disappearing usually after one or two generations. Then, too, even under ideal conditions for polygyny, most males, most of the time, have one mate and sometimes none at all.

In monogamous societies, all males are legally limited to one mate. The polyngynous tendencies, therefore, can be acted out only through premarital affairs and illicit extramarital relations, some of them institutionalized in prostitution.

The second most important limitation of polygynous tendencies is the need to obtain the female's approval for sexual encounters. The consent of the female is a condition sine qua non of sexual intercourse, with the conspicuous exception of rape. As we shall see, it would be disastrous for the female's sexual strategy to readily condone sexual intercourse with many males without discrimination of the male's propensity to invest in the common offspring.

Pornography creates a world of polygynous fantasy, in which there are always sufficient consenting females who unhesitatingly display their naked bodies, or body parts, thus signaling their preparedness for immediate sexual intercourse. Of course, this fantasy world of unlimited numbers of young, beautiful, seductive females, eagerly and enthusiastically engaging in every sort of sexual and violent activity, contrasts sharply with everyday reality.

Yet pornography is much more easily available for a sexual encounter than are most living females. Then, too, other males can share these pornographic heroines because the sexual favors 
of their females are not at stake. The pornographic heroines are nobody's female and everybody's female. Thus pornography does not formally interfere with the monogamous rules of society. No power struggle, no competition between males for sexual access to a specific female is involved, because mass production makes the pornographic dream easily available to everyone.

However, in order to understand the utter deception of this fantasy world, we have to analyze the female strategy as well.

\section{FEMALE SEXUAL STRATEGY}

Human females, as is true of all other mammalian and most avian females, invest heavily in their offspring. The investment of the human female is especially heavy because of the human neonate's utter helplessness. In fact, human babies need what we may call an extrauterine gestation. Under natural conditions, the human female's reproductive capacity is extremely limited: Howell (1979, p. 143), for example, found a total fertility of 4.28 for Dobe !Kung women. Females cannot profit from indiscriminate sexual promiscuity: a woman can bear no more children if she mates with many males than if she mates with one. What she needs in order to enhance her reproductive success is to find a genetically healthy male who would be able and willing to help share her heavy parental investment. The propensity of males to invest in the offspring is highly dependent on their certainty of paternity. Behavior of the female that casts doubt on the paternity of the investing male would diminish his inclination to further investment. Such diminution of investment interest can be seen as jeopardizing the chances of the survival of offspring. The female strategy, then, would have to evolve to be constantly attractive toward the investing male, who would be chosen for his ability and willingness to invest. This is offered as a theory, among others, of why the estrus would gradually disappear (Alexander and Noonan 1979).

It is then hardly surprising that there exists a fantasy world that fits the female strategy: The Harlequin Romance. Here males are generally depicted as devoted and unconditional investors in the female and their mutual children, never deviating from strict monogamy and eternal love to their wife. The male hero of the popular tel- evision series, Little House on the Prairie-a very humane, considerate, dependable and virile male-is a case in point. Many other examples can be found in the ten leading women's magazines, which claim readership of 149 million, a mirror view of the male's attraction to pornographic magazines. Different sexual strategies seem to create different preferences. However, this asymmetry is not complete. Despite arguments that women's romance is the same as men's pornography the Harlequin romance does not have an internal dynamic that pushes it toward the violent extremes of sadistic rape and sexual abuse of children, as pornography does. It certainly distorts reality but in a perhaps less inhuman manner (White 1970).

Attraction of and especially seductive behavior toward other males would be disastrous because it would endanger the first male's parental investment without securing the second's. A female may be seductive toward other males if she reaches the conclusion that her first choice was a mistake: the first male was a deceiver, proving unable or unwilling to invest-or impotent. Note: the male's investment does include his attitude toward the female as a mother.

It is important to point out at this stage of our discussion the inevitable impact of the mass use of birth control pills on female sexual behavior. Logically if reproduction is completely prevented by birth control and there is no offspring, there is no parental investment, either. In this case no asymmetry can exist between male and female parental investment. This asymmetry, however, is presented here as the crucial phenomenon determining the different sexual strategies of males and females. Consequently these differences are supposed by some to disappear under circumstances of the complete prevention of pregnancy.

Prevention, first of all, is not complete, either in the population or in the life-cycle of the individual female. While studies on contraception indicate an effect upon female sexual behavior by the use of the pill and other effective birth control means, it is difficult to tell yet how a new technological invention, however successful and widespread, can have had a decisive impact on behavior patterns that evolved biologically over millions of years and culturally through the millenia of documented cultural history. If it is true that differential parental investment is a powerful epigenetic rule that "directs the assembly 
of the mind" (Lumsden and Wilson 1981, p. 7), a plausible assumption is that most females in most populations will behave as though they have (or might have) children, even if they do not. That is why, even in the most sophisticated modern cultures (the East and West Coast of the United States, Sweden, Western Europe), we do not have a Huxleyian "Brave New World" of normative female promiscuity. A thirty-year-old technological invention cannot readily efface the whole biopsychological mechanism of a biologically (and culturally) evolved species (Shepher 1983, p. 19).

Nevertheless the wide use of birth control pills and the ensuing permissive ideology concerning sexuality did have impact on female behavior. One of the indicators is the fact thatas we have seen above-almost 8.6 million women are included in the readership of pornographic magazines. Though only sparse data concerning the motivation of those women are known to these writers, we may venture some informed guesses. Some probably read these. magazines in order to please their male partners, demonstrating thereby their sexual liberation; others do so from curiosity, following cultural pressure to negate any sex difference in behavior; some to understand their partners (men) better, or to assess the competition; and still others may have genuine interest because of their androgynous sexual attitudes. Some others may read the magazine because of its content of general interest (especially Playboy). It is possible that some of this female readership includes lesbians, just as male homoesexuals read Playgirl, although according to Symons (1979) homosexuals, both males and females, only change the object of their sexuality, not the patterns of it. Hence, since female arousal is generally less visual, lesbians may be but a small proportion of readers of pornographic magazines. The most important fact remains the extremely skewed male-female ratio of the readership of pornographic magazines.

Female behavior as depicted in both verbal and pictorial pornography is highly artificial, extraordinarily falsifying normal female behavior as it has evolved through both biological and cultural evolution. One function of this manufactured behavior is to create a world that removes the obstacles from the male's polygynous yearnings. Yet it does more than that.

\section{HYPOTHESES CONCERNING THE RESULTS}

First of all, in the real world most females including the magazine models themselves-are not picture perfect as measured by pornographic magazine standards. Secondly, as we just pointed out, even in our modern world of the birth control pill, enabling the almost complete separation of sex and reproduction, most females cannot easily counteract the heterosexual behavior patterns that have both biologically and culturally evolved. It is of course still difficult to find evidence for this statement, but Schofield (1976) found that the assumption of promiscuity in England is highly exaggerated. DeLamater and MacCorquodale (1979, p. 59) found that $40 \%$ of student females of the University of Wisconsin were virgins at the age of 18 -as against $25 \%$ of the males. The number of lifetime intercourse partners reflects the same sex difference: whereas $37 \%$ of the males had more than four intercourse partners, only $25 \%$ of the females had more than four partners. Thirty-seven percent of the females had only one partner, as against $20 \%$ of the males. Interestingly, the student population investigated proved to be less permissive than the control group of nonstudents.

From these verbal reports of interviewees on their sexual behavior we can only infer that most females àre not exhibitionist initiators and sexual adventurers. The confrontation with reality may leave the male reader-spectator feeling deceived, disillusioned, and frustrated. Among others, Kenrick and Gutierres (1980) found that judgment of average females' attractiveness or dating desirability is adversely affected by exposure of the judges to extremely attractive prior stimuli-even if this prior stimulus is clothed and not displaying explicit sexual seductiveness. If one adds the behavioral to the visual aspects (called by the authors the "Playboy Factor") one can assume that the adverse impact on the attractivenss of real-life females will be even greater.

The world of fantasy, especially in the form of modern mass products-paperback books, colorful magazines, video cassettes, all available to almost everyone-may create new standards of female behavioral attitudes. Seductive nakedness, the explicit exposure of the genitalia, and 
enthusiastic consent to any sexual pleasure gradually become a standard. Emotionally, male readers and spectators cannot help but make a comparison, even if cognitively they admit that their wives, girlfriends, or mistresses are different from the pornographic models. Because pornographic material is usually completely void of intellectual or sentimental connotations, the comparison is strictly limited to the erotic level of sexual arousal. In this comparison-that is, to be sure, subconscious - the true female can be said to always lose. The reasons are several. First, even for a noveity-chasing male, fantasy females-by their fantasy nature - offer more novelty than do real women. Secondly, even the sexually liberated female cannot compete with either the sophisticated equipment of the photo studio or the unlimited media imagination and innovation of the male pornographic writer.

Most males, despite propaganda to the contrary, are not Don Juans, and most females are not sexually sophisticated measured against some new standards of sadism, bestiality, anality, and so on. The result of fantasy-directed expectations may be a deterioration of male-female relationships, perhaps a deterioration of heterosexual comradeship and even love. Surely many males become disillusioned with their female partners' ability to arouse them. Any consistent use of pornographic magazines could also find readers thus disillusioned with their partners and their own sexual performance. The consequence for males may be, among other dysfunctions, conditional impotence. Some anecdotal evidence already exists to confirm this notion. Additionally, similar anecdotal data supports the idea that females, unable to compete with the models of pornographic fantasy, often become entangled in anxiety, reluctant to try to keep up with the new standard and gradually devoid of normal enjoyment of sexual relations. One of the authors has done extensive interviewing with women whose husbands/lovers were pornography consumers, and has found much anecdotal confirmation of wife/lover negativity toward the use of this material.

Another aspect has yet to be taken into account. The first is that sexuality based on pornography is completely detached from the basic function of sexuality: reproduction. Sexual arousal and carnal pleasure are the only aims sought by sexuality based on pornography. Where problems of arousal exist because of ex- tremely restrictive education and religious bigotry, pornography may serve as a therapeutic agent in behavioral therapy to help the patient in overcoming his or her inhibitions. Whether this use is a long-range good or not has yet to be established. However, its disinhibition value has been indicated by the use of pornography in sex therapy (Hartman and Fithian 1972; Money 1971a, 1917b; Caird and Wincze 1974; Cline 1974; Lobitz and LoPiccolo 1977; Bjorksten 1976; Pomeroy 1977; Wilson 1978). Arousal and pleasure, however minutely detailed, become boring: since the repertoire of foreplay and intercourse positions is not unlimited, habitual viewing often seems to result in a loss of arousal. We have found then, not illogically, that pornography is pushed to seek novelty: oral sex, anal penetration, sex with children, bestiality, pseudolesbianism, and sadistic sexuality. What this extension of repetoire tends to do to the male-female relationship is not difficult to imagine. Whereas oral sex may be part of the repertoire of normal male-female relations, one wonders whether the psychosexual mechanism of human beings evolved in the direction of sexual activities doomed by definition to failure from an evolutionary point of view?

At any rate, there seems to be a growing consensus that disillusionment usually creates frustration and frustration often creates aggression. Yet this aggression is not directed against the purveyor of pornography who created the fantasy world, but rather against real-life femalesand, increasingly, children.

Research aimed at investigating the relationship between the use of pornography and aggression against women has presented considerable evidence that pornography in general and aggressive pornography in particular seem to be casually related to aggression against women. Thus Malamuth and Check (1981) found that male subject's acceptance of interpersonal aggression against women was increased by exposure to films portraying violent sexuality. Such exposure also facilitated the acceptance of "rape myths." Malamuth and Donnerstein (1982) found in a well-controlled series of experiment that aggressive pornography increased male subject's aggression specifically against women. Nonaggressive pornography did not change the level of the subject's aggression against women and aggressive nonpornographic exposures increased aggressivity toward women 
to a considerably lesser degree than aggressive pornographic exposures. Zillmann and Bryant (in press) found that the more extravagant the pornographic stimulus (sadomasochism, bestiality, rape) the greater is the facilitation of aggression. They found that "after massive exposure to pornography, rape is apparently considered a lesser offense" and they add: "It can only be speculated that this effect results from the characteristic portrayal of women in pornography as socially nondiscriminating, as hysterically euphoric in response to just about any sexual or psychosexual stimulation, and as eager to accomodate seemingly any and every sexual request. Such portrayal, it seems, convinces even females of the hyperpromiscuous, accepting nature of women." Thus, massive exposure to pornography not only undermines men's respect toward women but even women's own selfrespect.

All above quoted evidence is experimental and the question remains whether there is any evidence that our analysis fits the data at the wider, societal level. Since 1970, when the U.S. Commission on Obscenity and Pornography stated that no evidence has been found that exposure to or use of explicitly sexual material plays a significant role in the causation of social and individual harms, pornography has changed considerably. John $\mathrm{H}$. Court (in press), in a recent survey of the literature, came to the conclusion that the statement of the committee cannot be verified in the present situation. $\mathrm{He}$ presents convincing evidence that:

1. Violent pornography widely available to the public increases the frequency of rapes; its restriction decreases it. The relationship is not a simple cause-effect relationship.

2 . Violent pornography may play some part towards the increase of nonsexual violence.

3 . The wide availability of nonviolent pornography supports the market and extends the demand for violent pornography because consumers usually move from nonviolent to violent types.

Another aspect is that of privacy. Even among polygynous primates, the mating couple tries to evade harassment by other individuals: the estrous female and her male escort sometimes go on long "safaris" [as long as 28 days! (Nishida 1979, p. 111)]. Gombe chimps form exclusive heterosexual pairs that tend to avoid areas frequented by other chimpanzees (McGinnis 1979 , p. 431). Consortship exists among orangutans as well (Galdikas 1979, p. 205; MacKinnon 1979 , p. 263), though with less intensity. Among humans, sexual intercourse is strictly limited to the exclusive presence of the mating couple, with the possible exception of rare Bacchanalian rites (Symons 1979, p. 67). Pornography, on the other hand, often makes sexual behavior public, contradicting a very basic, and evolutionary, stable human behavior pattern. The English royal family and public opinion are so upset, not so much because a Royal Prince consorts with a second-rate actress, but because the Prince's favorite lady's genitalia and sexual behavior were exposed to the public at large.

Pornography frequently depicts sexual encounters in which more persons than the mating couple interact. It thereby advertises highly unusual sexual activity, further glamorizing novelty sex and undermining stable human behavior patterns. Again, anecdotal information suggests that pornography may, in fact, induce couples bored with their marriages to experiment with group sex. The practice may bring initial exhilaration but will subside into an "inability" to live up to one's own psychosexual myths and "self illusions" (Bartell 1974, p. 198). Interestingly, males, whose initial propensity to engage in group sex activities is higher than that of females, appear to end up significantly disillusioned with its results.

Until now we have focused attention on the recipients of pornography. Although no reliable research on pornographic models and actors is known to the authors, a plausible assumption is that most women's sexual lives do not long benefit from their profession. Male participants constantly suffer from difficulties in achieving erection under the highly unusual circumstances of the presence of a film crew unless they are exhibitionists in the first place. Most filmed sexual activity, in fact, appears to be as a deception to the spectator. It is difficult to assume that such repeated experiences do not have a negative impact on the male performer's normal sexual activities.

Female performers probably fare worse. Although they do not have problems of erection, the very fact that their genitalia and sexual activity are exposed to the public probably highly curtails their chances for stable relationships. 
After an initial financial success period most of the rank and file actresses are pushed aside by younger, more attractive and less used competitors, and reduced to an unstable existence probably ending in a deteriorating life career. A few selected may be better off, mainly if they find a partner who is oblivious or disinterested in the model's past, or one who is excited by the knowledge that his wife was coveted or used by large numbers of males.

\section{THE SOCIOBIOLOGICAL EXPLANATION MODEL}

Modern pornography is, then, a contemporary answer to an old query: how to satiate the polygynous wolf and save the monogamous lamb. Facultative monogamy in humans reveals itself in an ethnographic paradox: in spite of the fact that an overwhelming majority of human cultures condone polygyny, most human individuals live in monogamy. The human infant is equipped with a minimal amount of genetically fixed behavior patterns but with enormous potential. Because, through the infant's extremely long maturation period, parental investment unprecedented in its length and breadth in the animal world is needed in order to bring the infant to maturation and to provide it with the unique means of human adaptation-culture. The human pair-bond, therefore, has evolved (Shepher 1978) as the statistically prevalent mating system in the human species. This is a classic sample of coevolution: natural selection working on the individual favors polygyny; cultural selection working on the group favors monogamy. The most "successful" cultures, in the sense of their having the largest populations (Europe, the Americas, Japan, China, India), are monogamous, and most individuals in polygynous cultures are monogamous as well.

Yet the human male is a reluctant monogamist. He is unable to suppress his polygynous tendencies completely. One of the evolutions of this reluctance may be pornography; the others, occasional adultery and prostitution. Until the modern age, pornography was a pastime of the few, rich, and higher-class males (India, the Arabs of the Abbasid Caliphate, Tokugawa and Meiji Japan, Victorian England) who possessed both the leisure time and the economic means to provide for their wife or wives and children. Modern pornography, however, as we have shown, is a mass commodity. It appears in a monogamous culture, and disorients its mating system.

The few, rich high-class males in the past and in other cultures were practically polygynous even in monogamous societies. Pornography was extremely expensive and therefore reached only a very few consumers in small quantities without exposing the customers to mass production. Modern pornography by its wide and constant distribution reaches the masses and continuously exposes all, indiscriminately, to a fantasy world that falsifies reality and contradicts basic and evolutionary stable behaviors. The Arab emir, the Japanese gentry, the rich Victorian gentleman could match somehow the fantasy world with court dancers and prostitutes and some even with extended harems. The modern male, however, must confront reality in his own home, with his wife or girlfriend and this reality cannot compete with the fantasy world of pornography. Arguably, as pornography use grows, male-female relationships deteriorate, aggression against women increases, sexuality is pushed towards more and more extravagant forms, more and more detached from sexuality's basic function in human life.

As we indicated by its title, our article has been an attempt at understanding. We presented some recent evidence, and a set of testable hypotheses. The investigation of human sexual behavior is, we know, one of the most difficult research topics from the methodological point of view. Yet if our approach to the problem will lead to valid and reliable research aimed at testing our hypotheses, we will have attained our goal. Good science starts with good questions. Good questions create good hypotheses. Whether we have succeeded in starting such a process will be shown by subsequent research, instigated by our ideas.

The authors are grateful to Dr. N. M. Malamuth for his bibliographic advice and for his comments on an earlier version of this article.

\section{REFERENCES}

Alexander, R. D., Noonan, K.M. Concealment of ovulation, parental care and human social evolution. In Evolutionary Biology and Human Social Behavior: An Anthropological Perspective, N. A. Chagnon and W. Irons (Eds.). North Scituate, MA: Duxbury Press, 1979. 
Bartell, Gilbert D. Group sex among the mid-Americans. In Beyond Monogamy, J. R. Smith and L. G. Smith (Eds.). Baltimore: The Johns Hopkins University Press, 1974, pp. 185-201.

Bat Ada, Judith (Reisman) Playboy isn't playing. In Take Back the Night Women on Pornography, $\mathrm{L}$. Lederer (Ed.) New York: Bantam Books, 1980, pp. 111-124.

Baum, M.J., Everett, B.J., Herbert, J., Keverne, E.B. Hormonal basis of proceptivity and receptivity in female primates. Archives of Sexual Behavior 6:173-192.

Bjorksten, Oliver J.W. Sexually graphic material in the treatment of sexual disorders. In Clinical Management of Sexual Disorders, J.K. Meyer (Ed.). Baltimore: Williams and Wilkins 1976, pp. 161-194.

Caird, W.R., and Wincze, J.P. Videotaped desensitization of frigidity. Journal of Behavior Therapy and Experimental Psychiatry 5(2): 175-178 (1974).

Cline, Victor B. Where Do You Draw the Line?: An Exploration into Media Violence, Pornography and Censorship. Provo, UT: Brigham Young University Press, 1974.

Court, J.H. Sex and violence: A ripple effect. In N.M. Malamuth and E. Donnerstein (Eds.). Pornography and Sexual Aggression New York: Academic Press (in press).

Daly, Martin, Wilson, Margo. Sex, Evolution, and Behavior. North Scituate, MA: Duxbury Press, 1978.

DeLamater, John, MacCorquodale, Patricia. Premarital Sexuality. Madison, WI: The University of Wisconsin Press, 1979.

Diamond, Irene. Pornography and repression: A reconsideration. In C.R. Stimpson and E.S. Person (Eds.). Women, Sex, and Sexuality. Chicago: University of Chicago Press, 1980, pp. 129-144.

Dworkin, Andrea.Pornography-Men Possessing Women. New York: Putnam's, 1981.

Galdikas, Birate M.F. Orangutan Adaptation at Tanjung Puting Reserve: Mating and Ecology. In The Great Apes, D.A. Hamburg and E.R. McCown (eds.). Menlo Park, CA: Benjamin Cummings, 1979, pp. 195-234.

Griffin, Suzanne. Pornography and Silence. New York: Harper and Row, 1981.

Hartman, W.E., Fithian, M.A. Treatment of Sexual Dysfunction. Long Beach, CA: Center for Marital and Sexual Studies, 1972.

Howell, Nancy. The Demography of the Dobe!Kung. New York: Academic Press, 1979.

Hrdy, Sarah Blaffer. The Woman that Never Evolved. Cambridge, MA: Harvard University Press, 1981.

Hyde, H.M. A History of Pornography. New York: W.S. Heinemann, 1964.

Kenrick, D.T., Gutierres, S.E. Contrast effects and judgments of physical atractiveness: When beauty becomes a social problem. Journal of Personality and Social Psychology 38(1): 131-140 (1980).
Lobitz, W.C., LoPiccolo, T. New methods in the behavioral treatment of sexual dysfunction. In: Handbook of Behavior Therapy with Sexual Problems, T. Fischer and H.L. Gochros (Eds.). New York: Pergamon, 1977, Vol. 1, pp. 7-14.

Lumsden, C.J., Wilson, E.O. Genes, Mind, and Culture: The Coevolutionary Process. Cambridge, MA: Harvard University Press, 1981.

MacKinnon, John. Reproductive behavior in wild orangutan populations. In The Great Apes, D.A. Hamburg and E.R. McCown (Eds.). Menlo Park CA: Benjamin Cummings, 1979, pp. 257-273.

Malamuth, N.M., Check, J.V.P. The effects of mass media exposure on acceptance of violence against women: A field experiment. Journal of Research in Personality 15: 436-446 (1981).

Malamuth, N.M., Donnerstein, E. The effects of aggressive pornography mass media stimuli. $A d$ vances in Experimental Psychology 15: 103-136 (1982).

McGinnis, Patrick R. Sexual behavior in free living chimpanzees: consort relationships. In The Great Apes, D.A. Hamburg and E.R. McCown (Eds.). Menlo Park: Benjamin Cummings, 1979.

Merton, R.K. Social Theory and Social Structure. Glencoe, IL: The Free Press, 1949.

Money, John. Pornography and medical education. In Macy Conference on Family Planning, Demography and Human Sexuality in Medical Education, Vernon Lippard (Ed.). New York: Josiah Macy, $1971 a$.

- The positive and constructive approach pornography in general sex education, in the home, and in sexological counseling. In Technical Report of the Commission on Obscenity and Pornography. Washington, D.C.: U.S. Government Printing Office, 1971b, Vol. 5, pp. 339-353.

Murdock, G.P. Ethnographic Atlas. Pittsburgh, PA: Pittsburgh University Press, 1967.

Nishida, Toshisada. The Social Structure of the Chimpanzees of Mahale Mountains. In The Great Apes D.A. Hamburg and E.R. McCown (Eds.). Menlo Park, CA: Benjamin Cummings, 1979, pp. 73-121.

Pomeroy, W.B. The use of audio-visual materials in therapy. In Progress in Sexology, R. Gemme and C. C. Wheeler (Eds.). New York: Plenum, 1977, pp. 209-213.

Schofield, Michael. Promiscuity. London: Victor Gollant $z, 1976$.

Shepher, Joseph. Reflections on the origin of the human pair-bond. Journal of Social and Biological Structures 1:253-264 (1978).

—. Incest: A Biosocial View. New York: Academic Press, 1983.

Statistical Abstracts of the United States. Washington, D.C.: U.S. Bureau of Census.

Symons, Donald. The Evolution of Human Sexuality. New York: Oxford University Press, 1979. 
Target Group Index. New York: Axiom Market Research Bureau, 1974, Vol. M-1.

- New York: Axiom Market Research Bureau, 1978, Vol. M-1.

Walker, C.E. Erotic stimuli and the aggressive sexual offender. In Technical Reports of the Commission on Obscenity and Pornography, Washington, D.C.: U.S. Government Printing Office, 1970, Vol. 7, p. 11.

White, Cynthia L. Women's Magazines 1693-1968. London: Michael Joseph, 1970.
Wilson, W. Cody. Can pornography contribute to the prevention of sexual problems? In The Prevention of Sexual Disorders; Issues and Approaches, C.B. Qualls, J.P. Wincze, and D.H. Barlow (Eds.). New York: Plenum, 1978, pp. 159-179.

Zillmann, D., Bryant, J. Effects of massive exposure to pornography. In N.M. Malamuth and E. Donnerstein (Eds.). Pornography and Social Aggression. New York: Academic Press (in press). 